\title{
Impact of varying levels of expertise on decisions of category typicality
}

\author{
KATHY E. JOHNSON \\ Indiana University-Purdue University, Indianapolis, Indiana
}

\begin{abstract}
Experts on domains of basic level object categories possess extensive knowledge of features used to both individuate and categorize groups of similar members. Two studies were conducted to determine the impact of high knowledge on intermediate and advanced experts' typicality decisions for basic and subordinate level category exemplars, and to investigate whether the pattern of influence of factors (in particular, central tendency and subjective familiarity) remained fixed throughout the continuum of expertise. Example goodness increased as a function of the level of specificity of the category for which typicality was rated. Subjective familiarity was the principal determinant of typicality for individuals with high knowledge, whereas central tendency was related to typicality when knowledge was not particularly high. Advanced and intermediate experts produced similar ratings of typicality, indicating that individuals' decisions of typicality do not change markedly once intermediate levels of competency have been attained. The incorporation of knowledge effects into models of semantic memory, as well as interactions among knowledge, psychological factors, and environmental factors in determining typicality, are discussed.
\end{abstract}

To become an expert on domains such as dogs, birds, or trees, one must spend a great deal of time observing or interacting with examples of those kinds of objects. An expert judge of dachshunds can rank-order candidates for "best of breed" on the basis of the dogs' gait, angulation of joints, and head shape, whereas novices would likely have difficulty even perceiving such differentiating features. From a psychological perspective, it is interesting to consider how such heightened knowledge and increased skill at perceptual discrimination among exemplars of very specific categories affect the graded structure of concepts. Specifically, it is unclear the extent to which expertise impacts decisions concerning which exemplars of a domain are more or less typical. Although evidence has been presented that subordinate level categories function as basic for experts (Johnson \& Mervis, 1997; Tanaka \& Taylor, 1991), it has not yet been determined whether experts' typicality gradients for subordinate categories that are relatively narrow in scope mirror novices' typicality gradients for categories at higher levels of abstraction.

Graded structure implies that membership in natural object categories such as bottle and plant is a matter of degree, with some exemplars judged to be more represen-

This research was supported by NIMH Grant MH53134 to K.E.J. and by generous support from the School of Science at IUPUI. Kelly Switzer, Joann Helferich, and Heather Clark assisted with data collection, transcription, and coding. I am grateful to the members of the Indianapolis Audubon Society for their enthusiastic support. Correspondence should be addressed to K. E. Johnson, Psychology Department, IUPUI, LD 124, 402 N. Blackford St., Indianapolis, IN $46202-$ 3275 (e-mail: kjohnso@iupui.edu). tative members or "better examples" of their categories than others (e.g., Barr \& Caplan, 1987; Kalish, 1995; Rips, Shoben, \& Smith, 1973; Rosch \& Mervis, 1975). Thus, soda bottles are better examples of bottle than bleach bottles and trees are more representative of plant than are cacti. Variations in category typicality have direct consequences for activities that depend on categorization, such as identification (McCloskey \& Glucksberg, 1978; Rosch, 1975), parent-child communication (Adams \& Bullock, 1986), concept learning (Mervis \& Pani, 1980; Rosch, Simpson, \& Miller, 1976), and inductive reasoning (López, Atran, Coley, Medin, \& Smith, 1997; Rips, 1975). A variety of factors have been shown to influence graded structure, including CT (Boster, 1988; Rosch, 1978; Rosch \& Mervis, 1975), subjective impressions of familiarity (Ashcraft, 1978; Barsalou, 1985, 1987; Lin, Schwanenflugel, \& Wisenbaker, 1990), and abstract goals or ideals (Lynch, Coley, \& Medin, 2000). The purpose of the present study was to determine whether the pattern of influence of particular factors remained fixed throughout the continuum of expertise, or whether certain factors exerted more pronounced effects on determinations of typicality when domain-specific knowledge is high. The domain of passerine birds (small birds that perch and generally sing) was selected as the focus of study because of its taxonomic depth and the availability of individuals with relatively high levels of relevant knowledge.

Hampton (1997) reviewed two competing theoretical frameworks that have been recruited to account for typicality effects in models of semantic memory. First, the associationist approach is based on principles of associative learning and emphasizes the learning history of 
the individual (e.g., Brooks, 1987; Chumbley, 1986). "Good" exemplars are those that have been most frequently associated with the category in the past. This approach would suggest that experts' heightened experience with a wide variety of domain-specific objects would result in a compression of judgments toward the "good example" end of the typicality continuum following repeated exposure to those objects. Alternatively, the similarity-based comparison approach entails a process of determining the degree to which an exemplar shares features or properties in common with stored examples of the concept (e.g., McCloskey \& Glucksberg, 1978; Rosch, Mervis, Gray, Johnson, \& Boyes-Braem, 1976; Smith, Shoben, \& Rips, 1974). Within this theoretical framework, "good" instances of a category are those that are most similar to the modal exemplar(s). Thus, individuals with varying levels of domain-specific knowledge should persist in rating as highly typical those instances that are most similar to other instances in terms of overall shape or shared features. Hampton (1997) demonstrated through a speeded categorization task that semantic memory is influenced by both associationist and similarity-based comparison processes, and he argued that integrating these two approaches into a common representational system is an important challenge for the field. It also seems critical that the role of expert knowledge be considered in the refinement of models of semantic memory, particularly given the current dominance of the concepts-in-theories view (Keil, 1994; Medin, 1989; Murphy, 1993; Murphy \& Medin, 1985). The results from the present study will help to elucidate how high levels of knowledge interact with central tendency, subjective familiarity, and instantiation frequency in determining category gradedness. Each of these factors is reviewed below, followed by a review of research on the effects of high levels of knowledge on conceptual structure.

\section{Determinants of Graded Structure}

Central tendency refers to the degree to which attributes (or correlations among attributes) possessed by category exemplars approximate average, mean, or modal values for particular dimensions (Barsalou, 1985; Smith $\&$ Medin, 1981). This construct is closely related to family resemblance (Rosch \& Mervis, 1975), where typicality is determined by the degree to which an exemplar (1) shares attributes in common with other category exemplars and (2) possesses attributes that contrasting categories do not. Individuals judge exemplars to be atypical when relations among properties deviate from the norm (Malt \& Smith, 1984), or when the overall shape of an object is markedly different from shapes of objects from coordinate categories (Kurbat \& Smith, 1994). Central tendency is most closely aligned with the similarity-based comparison explanation of gradedness effects. In the present studies, both ratings of overall similarity and measures of the degree to which features are shared among coordinate category exemplars are used as indices of central tendency. Since knowledge may influence the degree to which particular features are considered salient (Johnson \& Mervis, 1998; Medin, Lynch, \& Coley, 1997; Schyns, Goldstone, \& Thibaut, 1998; Wisniewski \& Medin, 1994), indices of central tendency for the present studies were generated by individuals with comparable levels of domain-specific knowledge.

Subject familiarity is the determinant of typicality that is most closely aligned with the associationist explanation of gradedness effects, and it is the factor that is most apt to vary dramatically between experts and novices. It seems possible that familiarity may play a substantial role in determining graded structure at the extremes of the knowledge continuum. Developmental data suggest that very young children (who have had little or no experience with many category exemplars) produce typicality ratings for common basic level objects that differ substantially from those generated by adults (Bjorklund, Thompson, \& Ornstein, 1983). On the other hand, the associationist approach would predict that experts, who have had extremely high levels of exposure to a broad variety of category instances, would compress judgments of frequently encountered exemplars toward the "good example" end of the continuum. The present study constitutes the first empirical investigation of the impact of subjective familiarity on experts' decisions pertaining to typicality.

Instantiation frequency refers to the frequency with which a particular exemplar is represented as an instance of its category in the environment (Barsalou, 1985, 1987). Instantiation frequency differs from familiarity in that the former concerns the actual frequency of exemplars in the environment, whereas the latter concerns individuals' subjective experiences with those exemplars. Thus experts may be equally familiar with exemplars that vary in terms of instantiation frequency due to their efforts to read about and actively seek out less common exemplars while in the field, or through their perusal of specialized books and journals. For novices, instantiation frequency and subjective familiarity may be correlated simply because novices are apt to notice those exemplars that are plentiful in the environment. Indeed, Barsalou (1985) found that for undergraduates, reported familiarity with specific exemplars contributed no unique typicality variance beyond that of instantiation frequency. Estimating instantiation frequency can prove challenging for researchers focusing on natural, rather than artificial, object categories. Word frequency (e.g., Kučera \& Francis, 1967) provides a rough estimate. However, word frequency generally has been not been found to be highly correlated with typicality ratings for natural object categories, particularly when ratings generated for unfamiliar words are excluded (Malt \& Smith, 1982; Mervis, Catlin, \& Rosch, 1976). More accurate, though less readily available sources of frequency data, are published inventories of local category exemplars. For example, Lynch et al. (2000) estimated instantiation frequency for Chicagoarea trees by summing data from recent local tree inven- 
tories. This approach was also adopted in the second study reported below.

\section{Impact of Knowledge on Conceptual Structure}

Experts are able to identify category exemplars with a high degree of specificity and accuracy (Johnson \& Mervis, 1997; Palmer, Jones, Hennesy, Unze, \& Pick, 1989; Tanaka \& Taylor, 1991), and classify and reason about objects in ways that novices do not (Medin et al., 1997). Experts' heightened experience puts them at a distinct advantage relative to novices in terms of both the amount of conceptual information stored in semantic memory and the manner in which that information is organized (Chi, Glaser, \& Farr, 1988; Gobbo \& Chi, 1986). Experts acquire a wealth of concepts at the subordinate (e.g., wren) and subsubordinate (e.g., marsh wren) levels, which may culminate in those levels functioning as basic (Johnson \& Mervis, 1997; Tanaka \& Taylor, 1991). Within some domains, experts and novices may actually represent different sets of features for the same categories. Experts can detect differences among object categories that novices frequently overlook, as features that differentiate among coordinate categories increase in salience through repeated exposure (Johnson \& Mervis, 1998; Proctor \& Dutta, 1995). If experts' awareness of features indicative of specific categories is heightened, it seems possible that typicality gradients associated with more specific categories will resemble novices' gradients for more general categories.

Finally, heightened knowledge is associated with increased awareness of features that are shared across concepts within a domain. Murphy and Wright (1984) found that experts' concepts related to child psychopathology were less distinctive than those of novices, as evidenced by the degree to which features were shared across multiple expert concepts. Johnson and Mervis (1998) also found that advanced experts on birds were highly knowledgeable of the dimensions along which songbirds could be confused, indicating that they were aware of features shared within and across subordinate kinds. It is unclear how experts' recognition of shared features across concepts would impact corresponding typicality gradients for those concepts. It seems possible that such awareness could counteract the effects of heightened distinctiveness, leading experts to consider all exemplars within a particular category as highly typical. That is, expert birders might be inclined to judge marsh wrens, sedge wrens, and house wrens as equally representative examples of the category wren on the basis of the degree to which features are known to be shared across exemplars.

The purpose of the present research was to determine the impact of expertise on ratings of typicality and to investigate whether the pattern of influence of central frequency (CT), subjective familiarity (SF), and instantiation frequency (IF) on decisions of typicality remains stable throughout the continuum of expertise, or whether particular determinants exert more powerful effects on typicality judgments when domain-specific knowledge is high. Associationist models of semantic memory would predict that SF, and perhaps IF, exerts strong effects on individuals' typicality judgments. Experts' heightened sensitivity to features that are shared across kinds would help to compress ratings of typicality toward the "good example" end of the continuum. On the other hand, similarity-based comparison models would predict that CT should impact judgments of typicality throughout the continuum of expertise. Increases in the salience of features indicative of specific categories should amplify intracategory differences and yield a wider range of typicality values for subordinate and subsubordinate categories than that generated by novices. Finally, it is possible that experts' heightened experience with a variety of domain-specific category instances could alter those dimensions along which similarity is computed (impacting CT) as well as determinations of typicality. Knowledge could exert independent effects on familiarity and central tendency, with both factors jointly influencing typicality determinations throughout the continuum of expertise. Study 1 was focused on the graded structure of the relatively inclusive passerine category. Attempts were made to disentangle levels of knowledge and levels of SF by including a set of exemplars that was not native to the United States. Study 2 addressed determinants of graded structure for more restricted generic or subordinate level categories. A secondary aim of these studies was to explore possible differences among groups of individuals at varying points along the expertise continuum. Study 1 involved comparisons among novices, intermediate experts, and advanced experts, and Study 2 compared intermediate and advanced experts.

\section{STUDY 1 \\ Impact of Increased Knowledge on Typicality Ratings of Passerine Category Exemplars}

Examining the relative impact of SF on the gradedness of experts' concepts presents a challenge to researchers, since these variables inevitably are confounded with levels of knowledge. This problem was circumvented in the present study by having individuals assign typicality ratings to both local passerine exemplars and Australian exemplars that had not previously been encountered by expert participants. CT was determined through ratings of overall similarity generated by individuals with comparable levels of knowledge. Pictures were used to represent category exemplars rather than labels because none of the participants were expected to be familiar with the subordinate category names of Australian exemplars. It was expected that CT would be a more powerful determinant of graded structure for nonexperts than for experts, based on previous work with adults possessing only average levels of domain-specific knowledge (Barsalou, 1985; Rosch \& Mervis, 1975). The effect of SF was predicted to be more pronounced among advanced experts than among intermediate experts, given advanced experts' greater experience with passerines. 


\section{Method}

\section{Participants}

Thirty-two experts and 20 novices participated in the typicality rating task. Experts were divided into advanced and intermediate expert groups on the basis of peer ratings of knowledge. Questionnaires were mailed to 31 active birders who belonged to the Indianapolis Audubon Society. Questionnaires listed the names of the 31 birders, and recipients were asked to anonymously rate each of their peers' proficiency at visually identifying passerine birds. Recipients were instructed to provide ratings only for those individuals with whom they had a history of shared birding experience. Ratings of passerine knowledge were generated on a 7-point scale $(1=$ knows very little; 7 = one of the most knowledgeable people I've ever encountered). Twenty-seven of the 31 questionnaires were returned. Two additional birders were recruited by word of mouth once the study began, and these individuals were assigned ratings by study participants when they came into the lab. Of the 33 individuals who received peer ratings, 32 participated in the study. The 12 individuals who received the highest mean ratings were classified as advanced experts $(M=6.57)$, and the remaining 20 individuals were classified as intermediate experts $(M=5.30)$. Advanced experts averaged 30 years of birding experience, and intermediate experts averaged 22 years of experience. Experts received gift certificates to local wild bird stores in return for their participation. The novice group included 24 undergraduates enrolled in psychology courses at IUPUI who received course credit for participating. All novices rated their own knowledge of birds as lower than average.

An additional 10 experts and 24 novices were recruited for a similarity rating task used to derive the $\mathrm{CT}$ indices. Again, novices were recruited from introductory psychology classes for course credit. Experts were recruited through electronic mail lists, newspaper notices, and through Indianapolis Parks Department birding activities. Since these individuals did not always know each other socially as the former group of experts did, only self-ratings of knowledge level were collected $(M=5.62)$. These 10 individuals averaged 18 years of birding experience and were paid for their participation.

\section{Materials}

Realistic color illustrations of 18 North American species and 18 Australian species of passerines were digitized and presented to scale on a color computer monitor against a white background. All North American species were recorded as residents or migrants in the metropolitan Indianapolis area (Keller \& Keller, 1993). Australian species were indigenous to Australia alone or to the AustraloPapuan-New Zealand region. Species were selected to include a wide range of families from the order Passeriformes and are listed in Appendix A. All exemplars shared the characteristic 3-plus-1 toe structure and relatively small size of perching birds. However, the exemplars varied in terms of their colors, postures, beak structures, tail lengths, and the presence or absence of crests.

\section{Procedure}

Overall similarity rating task. Ratings of overall similarity were collected for sets of 18 North American passerines and 18 Australian passerines (Appendix A). Within each set, the 153 possible pairs of the 18 exemplars were presented individually on a color monitor, and participants were asked to rate the similarity of the pair on a 7 -point scale $(1=$ extremely similar $;=$ not at all similar) by considering "all aspects of the bird, including color, shape, size, and parts of the body." For each rater, similarity indices were calculated for each bird by averaging the similarity ratings involving that bird across the 17 pairs in which it appeared. These individual similarity indices were then averaged across raters with comparable levels of knowledge, creating two overall similarity indices for each of the 18 species within a set: one novice-CT index and one expert-CT index. Twelve novices rated each set of passerines. The 10 experts rated both sets of 153 pairs, although the sets were blocked and the order in which the Australian versus North American sets were presented was counterbalanced. A subset of 20 of the 36 species (10 North American species, 10 Australian species) was used during the typicality and familiarity rating tasks described below. Species were selected in order to maximize the range of $\mathrm{CT}$ ratings represented and to ensure that several "backyard" species were included with which even novices should be moderately familiar. CT values were multiplied by -1 to facilitate interpretation of the results (i.e., a high CT score indicates that an exemplar was highly similar to coordinate exemplars). Figure 1 presents examples of North American and Australian species assigned relatively high and relatively low CT scores by both experts and novices.

Typicality and familiarity rating phase. Participants first generated typicality ratings for each of the 20 species. Instructions were adapted from Rosch and Mervis (1975), and participants were asked to rate each of the pictured species in terms of how good an example it was of the category passerine bird. All of the novices and the 2 intermediate experts who requested further clarification were informed that "passerine birds" were "songbirds," or members of the taxonomic grouping of smaller birds that sang and perched. Ratings were made on a 7-point scale $(1=$ a very good example of your idea of what a passerine bird is; 4 = fit moderately well; and 7 = fits very poorly with your image of what a passerine bird is, or is not a member at all). Participants were told to use the other numbers of the 7-point scale to indicate intermediate judgments. The rating scale was presented at the top of the screen throughout the rating task. Participants were instructed to type their ratings onto the keyboard following each presentation of a passerine exemplar. Two random orders of the 20 exemplars were created, and half of the participants received each of the two orders. North American and Australian species were interspersed throughout the rating task, and no information was provided to participants concerning the residency status of the birds depicted.

Following an unrelated intervening task, participants were asked to rate their subjective level of familiarity with each of the 20 species. Two ratings were generated for each bird in order to account for differences between familiarity developed through direct interactions with species (i.e., in the field) and familiarity developed through indirect exposure to species through books, videotapes, or other media. Participants were informed that "for some birds, these two ratings may be identical. You may have had many encounters with the bird and you may also have read extensively about it. For other birds, the two ratings may be quite different. You might have read extensively about a particular bird without ever encountering it in the field." Ratings were generated along a 7-point scale $(1=$ highly familiar $7=$ not at all familiar $)$. Again, ratings were made on a computer, with the rating scale presented above each pictured species. Again, two random orders of presentation were generated, and birds were always presented in a different random order from that used during the typicality rating task. After all ratings had been generated, the series of 20 birds was presented a third time for a naming task that provided an additional index of familiarity. Participants were asked to name each bird as accurately as possible and were encouraged to respond "don't know" if they were unsure of a particular bird's name.

\section{Results}

The results are divided into three sections. First, the names produced and the mean familiarity ratings generated for local and Australian species were analyzed to ensure that the typical confound between level of domainspecific knowledge and level of SF had been eliminated. 

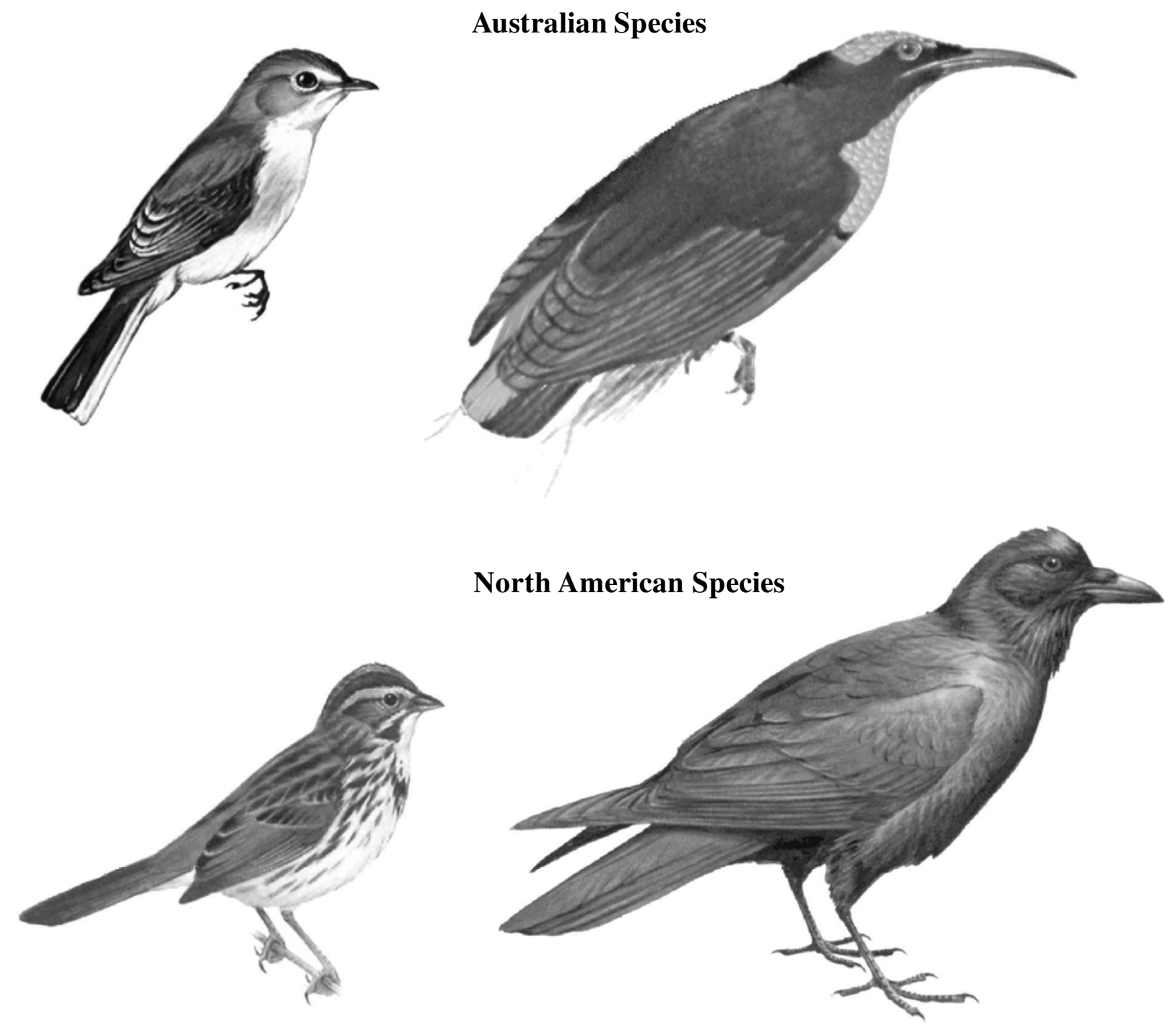

Figure 1. Examples of Australian and North American passerines (species with higher CT values appear on the left).

Second, the degree to which CT and SF were related to typicality estimates across the three knowledge groups was considered. IF was not included in this analysis because there was, by definition, no variance for the Australian exemplars. Finally, differences across knowledge groups in the distribution of typicality values assigned to passerine exemplars are reported. Mean ratings generated for the set of 20 exemplars are presented in Appendix B.

\section{Variations in Familiarity Across Groups}

A one-way analysis of variance (ANOVA) performed on the number of correct names produced for American passerines yielded a significant effect of knowledge group $[F(2,57)=335.49, p<.001]$. Scheffé tests indicated that novices $(M=2.43)$ produced significantly fewer names than either intermediate experts $(M=8.89)$ or advanced experts $(M=9.73)$. However, none of the participants generated correct species names for the Australian passerines. Three of the advanced experts reported being moderately familiar with between two and five Australian species through reading books and journals or watching nature documentaries. None of the participants indicated that they had seen any of the Australian species in the field. Interestingly, 2 advanced experts and 6 intermediate experts misidentified at least one Australian species with a relatively high CT value as an exemplar of a local species (e.g., the yellow white-eye was almost always identified by these individuals as a "white-eyed vireo"). No such misidentifications were generated for Australian exemplars with lower CT values.

To confirm that assignments of participants to knowledge groups were correlated with the degree to which only local species were considered familiar, a mixed 3 (level of knowledge) $\times 2$ (residency status) ANOVA was conducted on the mean familiarity ratings generated 
Table 1

Raw Correlations Among Typicality Ratings, Central Tendency, and Subjective Familiarity: Passerine Category

\begin{tabular}{ccc}
\hline Correlation & Central Tendency & Subjective Familiarity \\
\hline Advanced Experts: & & $.60^{* *}$ \\
Typicality Ratings & $.44^{*}$ & -.11 \\
Central Tendency & & $.57 * *$ \\
Intermediate Experts & & .01 \\
Typicality Ratings & .47 & \\
Central Tendency & & -.27 \\
Novices & & .14 \\
Typicality Ratings & $.55^{* *}$ & \\
Central Tendency & & \\
\hline
\end{tabular}

Note- ${ }^{*} p=.05 ; \quad{ }^{* *} p<.01$.

across the 10 exemplars within each resident set. There were main effects of both knowledge level $[F(2,49)=$ $25.73, p<.001]$ and residency status $[F(1,49)=882.71$, $p<.001]$, as well as a significant interaction between the two variables $[F(2,49)=44.99, p<.001]$. Australian exemplars were less familiar than local exemplars. The significant interaction was explored through separate one-way ANOVAs performed on North American and Australian exemplars. Both advanced and intermediate experts rated themselves as significantly more familiar with North American species than novices did (Scheffé tests significant at $p<.001)$. However, there was no significant knowledge group effect on familiarity ratings for Australian exemplars, indicating that we were successful in eliminating the typical confound between level of domain-specific knowledge and level of SF.

\section{Determinants of Graded Structure}

To compensate for differences in experts' and novices' utilization of the rating scale in their determinations of typicality and familiarity, participants' ratings were standardized by subtracting each individual's mean response from each rating, and then dividing this difference by the standard deviation of that individual's responses. In cases where experts indicated different levels of SF based on direct and indirect exposure to species, the rating indicating the higher degree of familiarity was consistently used. To facilitate interpretation of the results, all ratings were multiplied by -1 so that higher scores would reflect higher values along each of these dimensions. For each of the three groups of participants, exemplar typicality ratings and exemplar SF ratings were calculated by averaging across participants at the same level of knowledge. Mean typicality ratings were then correlated with the CT index and mean SF ratings for each of the 20 species. The CT indices generated by novices and experts were strongly related $(r=.59, p<$ $.01)$. Nevertheless, the novice-CT index was used in the analysis of novices' typicality ratings, and the expert-CT index was used in the analyses of ratings generated by both groups of experts.

Raw correlations and their significance levels are presented in Table 1. CT was significantly related to typi- cality ratings for all three knowledge groups, although this relation was strongest for individuals in the novice group. SF ratings were associated with typicality ratings for both groups of experts, but not for novices, suggesting that familiarity is strongly associated with typicality decisions only when knowledge levels are relatively high. ${ }^{1}$ It is important to point out that this result may have been an artifact of the procedure used. Since experts were presented with sequences of American exemplars interspersed with Australian exemplars, ratings of the American exemplars may have been compressed due to a simple contrast effect: If birds were readily recognized they were considered more typical. Presenting separate blocks of familiar and less familiar exemplars to different groups of experts could help to elucidate the true impact of familiarity on typicality ratings. We chose the present method because of the relatively small number of expert participants involved. Additional support for the finding that CT is an important determinant of typicality when knowledge is low was obtained through an analysis of the relation between experts' typicality ratings for Australian exemplars and CT scores. For both advanced experts $(r=.62, p=.05)$ and intermediate experts $(r=.66, p=.04)$, this relation was positive and significant, indicating that when knowledge is low, the degree to which an exemplar is similar to other exemplars is predictive of whether or not that exemplar is considered a good example of a category. When domainspecific knowledge is high, exemplars that are considered most familiar are generally judged to be the best examples.

\section{Effects of Knowledge on Intracategory Variation}

In addition to examining interrelations among typicality, familiarity, and CT across the three knowledge groups, we were also interested in differences across knowledge groups in the degree to which ratings were compressed toward the "good example" end of the typicality continuum. Two alternate scenarios pertaining to the effects of high knowledge on the degree of intracategory variation in typicality ratings were proposed on the basis of previous research. On the one hand, high knowledge could exacerbate subtle differences among exemplars, leading to an amplification of the degree to which category exemplars vary in terms of goodness of example. On the other hand, frequency of exposure could strengthen semantic associations for all domain exemplars, which, coupled with experts' knowledge of shared features, could compress ratings of typicality toward the high (good example) end of the gradedness continuum. To examine this question, a median split on CT was used to divide exemplars within each residence set into a high central tendency (HCT) or a low central tendency (LCT) group. ${ }^{2}$ Mean typicality ratings across the five exemplars within each set were analyzed in a mixed 3 (level of knowledge) $\times 2$ (residency status) $\times 2(\mathrm{CT})$ ANOVA, with knowledge group as the between-groups factor and both residency status and CT as within-groups factors. Unaltered typicality ratings (i.e., ratings were not multiplied by 

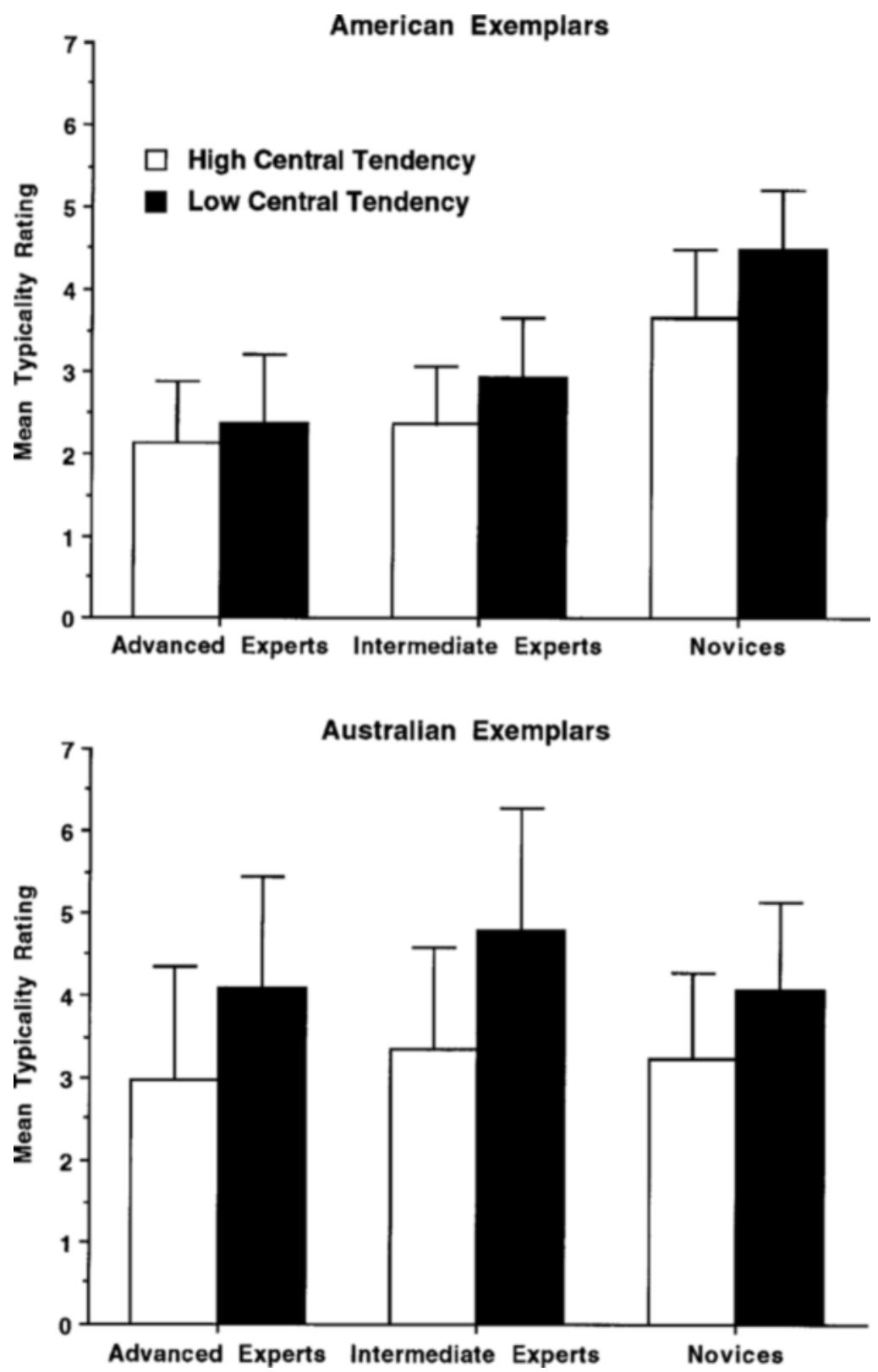

Figure 2. Mean typicality ratings generated across the three knowledge groups. (Lower ratings indicate more typical instances.)

-1) were used as the dependent measure in this analysis to facilitate interpretation of the means and standard deviations depicted in Figure 2. All main effects were significant: level of knowledge $[F(2,49)=6.28, p<.01]$, residency status $[F(1,49)=26.91, p<.001]$, and $\mathrm{CT}$ $[F(1,49)=68.01, p<.001]$. Overall, novices rated passerines as less good examples than either group of experts did; American passerines were considered better examples than Australian passerines; and HCT exemplars were considered better examples than LCT exemplars. These effects were tempered by interactions between level of knowledge and residency status $[F(2,49)$
$=18.51, p<.001]$, and between residency status and CT $[F(1,49)=10.65, p<.01]$. The three-way interaction among level of knowledge, residency status, and CT approached significance $[F(2,49)=2.91, p=.06]$. These effects were explored further through the separate mixed and repeated measures ANOVAs described below.

Ratings of familiar passerines. Mean typicality ratings assigned to groups of HCT and LCT local passerines were analyzed in a $3 \times 2$ mixed ANOVA, with level of knowledge as the between-groups factor and CT as the within-groups factor. The main effects of level of knowledge $[F(2,49)=30.87, p<.001]$ and $\mathrm{CT}[F(1,49)=$ 
Table 2

Raw Correlations Among Typicality Ratings, Central Tendency (CT), Instantiation Frequency (IF), and Subjective Familiarity (SF): Subordinate (Genus) Level Categories

\begin{tabular}{llll}
\hline \multicolumn{1}{c}{ Correlation } & CT & IF & SF \\
\hline Advanced Experts: & & & \\
Typicality Ratings & .39 & $.45^{*}$ & $.66^{* *}$ \\
CT & & .10 & .27 \\
IF & & & $.75^{* * *}$ \\
Intermediate Experts & & & \\
Typicality Ratings & .41 & $.51^{*}$ & $.65^{* *}$ \\
CT & & .10 & .10 \\
IF & & & $.92^{* * *}$ \\
${ }^{*} p<.05 .{ }^{* *} p<.01 .^{* * *} p<.001$. & &
\end{tabular}

$55.39, p<.001]$ were both significant, as well as the level of knowledge $\times$ CT interaction $[F(2,49)=5.29, p<$ $.01]$. Scheffé tests revealed that novices rated local passerines as significantly less good examples than either group of experts did, indicating that high knowledge did result in a compression of ratings toward the "good example" end of the scale. Advanced and intermediate experts did not differ in their ratings of familiar exemplars. Separate repeated measures ANOVAs revealed that for each knowledge group there was a significant main effect of CT [advanced experts: $F(1,11)=9.14, p=$ .01 ; intermediate experts: $F(1,19)=28.24, p<.001$; novices: $F(1,19)=33.99, p<.001]$. The interaction between level of knowledge and CT arose because novices differentiated more between HCT and LCT familiar exemplars than either group of experts did.

Ratings of unfamiliar passerines. A parallel $3 \times 2$ mixed ANOVA was conducted on the mean typicality ratings assigned to groups of HCT and LCT Australian passerines. The only significant effect to emerge was the main effect of CT $[F(1,49)=39.96, p<.0001]$. As expected, all three groups rated LCT exemplars as less good examples of passerines than HCT exemplars. No group differences emerged as a function of domain-related knowledge. Thus, the compression of scores toward the "good example" end of the rating scale obtained only for experts' judgments of familiar passerines. When presented with species not encountered regularly, the distribution of experts' ratings was similar to that of novices. As predicted, when exemplars were unfamiliar, individuals in all three knowledge groups tended to rate exemplars that were relatively dissimilar (LCT) as poor examples.

In sum, high levels of knowledge were associated with two patterns of results pertaining to assignments of typicality values to passerine exemplars. First, determinations of example goodness were clearly affected by individuals' levels of domain-relevant knowledge. CT was associated with typicality throughout the continuum of knowledge, but its relation was strongest when domainspecific knowledge was low. SF was most strongly related to experts' ratings of typicality, constituting the first empirical evidence that familiarity can be an important determinant of graded structure. Second, experts' assignments of ratings to species that were en- countered regularly were compressed toward the "good example" end of the scale relative to ratings of nonexperts, in keeping with associationist models of semantic memory. Repeated experiences with passerines may enhance the degree to which distinguishing features are perceived as salient, yet at the same time reinforce the extent to which all songbirds are believed to share certain core properties. Contrary to initial predictions, advanced and intermediate experts generated virtually identical patterns of results, suggesting that the obtained effects of knowledge on determinations of typicality obtain at least by the time intermediate levels of expertise have been acquired. In Study 2, differences between intermediate and advanced experts were considered more likely because typicality judgments were obtained for substantially narrower categories (corresponding to the level of genus).

\section{STUDY 2}

\section{Determinants of Typicality Within Subordinate (Genus Level) Categories}

Intracategorical structure varies considerably as a function of the degree to which categories can be parsed into subcategories (Storms \& De Boeck, 1997). Within subordinate level categories, differences among coordinate exemplars are manifest through extremely subtle modifications of parts, rather than through global features (e.g., shape) or behaviors (Tversky \& Hemenway, 1984). There have been no investigations of variations in degree of representativeness among natural categories at these very specific levels of inclusiveness. It was expected that the range of variation in typicality ratings for exemplars included within subordinate categories would be compressed relative to the range exhibited in the previous study, given that members of more specific categories are more similar to each other than are members of more general categories (Murphy \& Brownell, 1985; Rosch et al., 1976). We were also interested in the factors that predicted experts' typicality ratings within these relatively narrow categories. Because past research has indicated that advanced and intermediate experts differ primarily in terms of the richness of category representations at the species level (Johnson \& Mervis, 1997), it

Table 3

Second-Order Partial Correlations Reflecting Unique Predictive Power of Central Tendency (CT), Instantiation Frequency (IF), and Subjective Familiarity (SF) on Typicality Ratings: Subordinate (Genus) Level Categories

\begin{tabular}{ccc}
\hline Correlation & Raw Correlation & Partial Correlation \\
\hline Advanced Experts & & \\
Typicality_CT & .39 & .28 \\
Typicality_IF & $.45^{*}$ & -.04 \\
Typicality_SF & $.66^{* *}$ & $.48^{*}$ \\
Intermediate Experts & & \\
Typicality-CT & .41 & $.48^{*}$ \\
Typicality-IF & $.51^{*}$ & -.36 \\
Typicality-SF & $.65^{* *}$ & $.59^{*}$ \\
\hline
\end{tabular}


was anticipated that the determinants of typicality might differ across the two expert groups. For intermediate experts who have interacted with fewer instances of subordinate exemplars than advanced experts, CT was expected to be strongly related to typicality ratings. For advanced experts, SF was again predicted to be the principal determinant of graded structure. IF, as assessed through published inventories of local species, was included as an additional factor in order to assess the degree to which it informed typicality above and beyond the impact of familiarity.

\section{Method \\ Participants}

Participants included the 32 experts who completed the typicality rating task for Study 1 . Novices were not included because of their lack of familiarity with the subordinate level categories for which typicality gradients were assessed. The order in which tasks from Studies 1 and 2 were presented to experts was counterbalanced across participants.

\section{Stimuli}

Five species from each of four subordinate categories were identified so that all species were native to Indianapolis and represented a range of IF values (Keller \& Keller, 1993). Booklets were created that listed the five exemplars for a given category on the same page, in conjunction with the rating scale and instructions, as described below. Two different stimulus sets of category names and two different orders of category names within each stimulus set were created. Crossing the two orders with the two stimulus sets yielded four different test booklets, each containing five exemplars from each of two subordinate categories.

\section{Procedure}

Half of the participants ( 5 advanced experts, 11 intermediate experts) generated typicality ratings in reference to exemplars from Stimulus Set 1, and the other half generated ratings in reference to exemplars from Stimulus Set 2. Exemplars from the alternate stimulus set were presented to each participant in a feature listing task designed to yield an estimate of CT for the exemplars included within each category. Due to the small number of species included within each category, we believed that analyses of shared features would yield a more stable index of CT than similarity ratings would. Participants did not generate typicality ratings for the entire array of 20 exemplars because of the possibility that ratings would be affected by performing the feature listing task.

Feature listing task. The feature listing task was conducted verbally in order to make it as easy as possible for participants to list as many features as they were able for each of the 10 exemplars in the stimulus set for which typicality ratings were not made. Exemplars were blocked by subordinate category, and there were two orders of blocks and two orders of exemplars within each block that were counterbalanced across participants. Experts were instructed to list as many characteristics of each species as they could think of and were told to "consider each bird's behaviors, habitat, appearance, and sounds, as well as any other characteristics that might be shared by members of the species." Responses were audiotaped and subsequently transcribed.

Transcripts from the feature listing task were used to create indices of CT for each of the 20 exemplars. First, feature lists generated by participants were compiled into 20 separate master lists. Two independent raters subsequently went through each list and deleted features that were clearly the subjective impressions of particular individuals (e.g., my favorite kind of warbler; the vireo whose song I have the most difficulty identifying). The remaining features were divided into separate propositions, each of which cor- responded to one unit of information (e.g., "common permanent resident" listed for song sparrow was divided into the two propositions "common resident" and "permanent resident"). Reliability between the two raters (agreements/agreements plus disagreements) on the contents of the final feature lists was .93, and disagreements were resolved through discussion. The index of CT was derived from the corpus of remaining propositions on the basis of procedures used by Rosch and Mervis (1975). Each feature listed for each of the 20 exemplars received a raw score from 1-5, representing the number of species within the genus that shared that feature. For example, if "migrant" was included on the master lists of three vireos, each instance of "migrant" would receive a raw score of 3 . The natural logarithms of these raw scores were then summed across the features listed for each species to yield indices of CT that reflected the degree to which exemplars shared features in common with coordinate species. ${ }^{3}$ The exemplars included in each of the two stimulus sets and their respective mean ratings are listed in Appendix C.

Rating generation task. Ratings of typicality and SF were collected using the same methods as described for Study 1, with two exceptions. First, participants were instructed to generate typicality ratings in reference to category labels, rather than pictured exemplars. Because coordinate species share so many physical features in common, using labels helped to ensure that experts felt free to consider a variety of behavioral (e.g., song, flight, habitat) dimensions when rating typicality. Names of the five exemplars from within a particular category were printed on the same page of a prepared booklet with the rating scale and instructions appearing at the top of each page. Second, participants were instructed to generate their ratings in reference to subordinate level categories (e.g., "How good an example of sparrow is X?"). SF ratings were collected after an intervening task. Again, participants were instructed to generate two SF ratings: one for familiarity derived through direct experience in the field and one derived through indirect experience (e.g., through books, videotapes, or electronic media). In subsequent analyses involving subjective ratings of familiarity, the higher of these two scores (indicating the greater degree of familiarity) was consistently used.

\section{Results}

Preliminary analyses conducted to determine whether the order in which tasks from Studies 1 and 2 were presented influenced any of the dependent measures in either of the two studies failed to yield any significant effects of task order (all $p s>.40$ ). Thus, data were collapsed across task order in all reported analyses. It was expected on the basis of previous research that advanced experts would be significantly more familiar with species (subsubordinate) level category exemplars than intermediate experts (Johnson \& Mervis, 1997). To confirm this expectation, a one-way ANOVA was conducted on the mean familiarity ratings generated for species exemplars. A significant main effect of knowledge group emerged $[F(1,30)=11.74, p<.01]$, indicating that advanced experts indeed reported themselves to be significantly more familiar with species exemplars than intermediate experts did.

\section{Determinants of Typicality Within Subordinate Level Categories}

We first explored the degree to which CT, IF, and SF accounted for typicality ratings assigned to more specific subordinate level categories. IF was included in this analysis to determine the degree to which it accounted for variance in typicality ratings above and beyond the 
effects of SF. Although SF and IF are highly correlated for novices, it seemed plausible that they might be less so for experts, who devote a great deal of time to seeking out species that are particularly rare. Levels of IF were derived from published reports on the frequencies with which particular species were sighted in the metropolitan Indianapolis area throughout the year (Keller \& Keller, 1993). Published residency status codes and their assigned numerical values on the IF scale are presented in Appendix C. As in the previous study, ratings of both SF and typicality were multiplied by -1 so that higher scores reflected higher values along these dimensions.

For each group of experts, indices of each exemplar's typicality and SF were computed by averaging across the individuals within that knowledge group who generated ratings for a particular stimulus set. Mean typicality ratings were then correlated with the CT index (reflecting the degree to which each exemplar shared features in common with coordinate species, as described above), the IF index, and mean SF ratings (again averaged across the individuals within a particular knowledge group who generated ratings for that stimulus set). Raw correlations and their significance levels are presented in Table 2. Both IF and SF ratings were significantly correlated with typicality ratings for both groups of experts. CT was also positively related to typicality ratings for each knowledge group, although these correlations were not significant. IF and SF were significantly correlated for both groups of experts. Although it had seemed plausible that for advanced experts, IF and SF would be separable (given that advanced experts might spend the majority of their time reading about and seeking out species that are relatively scarce), it appears that these variables remain highly correlated throughout the continuum of expertise.

Due to intercorrelations among the factors considered, second-order partial correlations were computed to determine the extent to which these raw correlations were attributable to variance shared among CT, IF, and SF. Comparisons between raw and second-order partial correlations are presented in Table 3. For both advanced and intermediate experts, the original relations between typicality ratings and IF were eliminated once $\mathrm{CT}$ and SF ratings were partialed out. Only SF ratings continued to contribute unique variance to the graded structure of advanced experts' subordinate level categories. The major difference between advanced and intermediate experts concerned the relation of CT to typicality ratings. For advanced experts, CT was not significantly related to typicality ratings. For intermediate experts, both $\mathrm{CT}$ and SF impacted typicality. Indeed, CT became a better predictor of typicality after IF and SF were partialed out.

\section{Between-Level Comparisons of Typicality Ratings}

Mean typicality ratings assigned by advanced and intermediate experts to exemplars of subordinate level categories were compared with those assigned to resident exemplars from the more general category of passerine in Study 1. In the previous study, advanced and intermediate experts tended to rate local birds as considerably more typical examples of passerine than novices did. This result led to the conclusion that high levels of knowledge compress exemplars toward the "good example" end of the continuum, perhaps due to increased frequency of exposure or to the heightened salience of shared features. Within subordinate level categories, exemplars tend to share even higher proportions of features. Therefore, it is quite likely that knowledgeable individuals will judge most species exemplars to be equally good examples of their respective genera, despite the fact that particular clusters of features may have gained salience through years of field identification. A content analysis of the individual features generated by each participant revealed that $43 \%$ of the features listed by advanced experts and $27 \%$ of the features listed by intermediate experts were shared by two or more species within the genus (e.g., "it has the same posture as the other wrens," "its coloring is similar to the Kentucky [warbler]").

To compare ratings across hierarchical levels and to determine whether there were differences in the mean typicality ratings of advanced and intermediate experts, two scores were calculated for each expert. The first represented the mean typicality rating assigned to the 10 resident (i.e., American) passerines from Study 1. The second represented the mean typicality rating assigned to the 10 species level exemplars from the present study. These scores were compared in a mixed 2 (knowledge group) $\times 2$ (stimulus set) $\times 2$ (category level: passerine vs. genus level) ANOVA, with both knowledge and stimulus set as between-groups factors. The only significant effect to emerge from this analysis was a main effect of category level $[F(1,28)=24.35, p<.0001]$. As predicted, experts tended to rate species as better instances of their genus level categories than they rated them as examples of the more general category of passerine. Indeed, $50 \%$ of the advanced experts and $45 \%$ of the intermediate experts gave ratings of 1 (i.e., "very good example of X") to at least 4 of the 5 species exemplars within a subordinate category. Advanced and intermediate experts did not differ in their mean typicality ratings, despite their differences in reported familiarity with subordinate category members. It is important to point out that this result follows logically from the fact that the categories of birds are hierarchically structured. Members of very specific categories share most features in common and thus would presumably be rated as highly typical. However, only experts would generally be capable of making such judgments, since novices are simply not knowledgeable about subsubordinate categories.

\section{GENERAL DISCUSSION}

Experts on object domains possess rich knowledge concerning the intrinsic and extrinsic features indicative of very specific subcategories and the interrelations among those subcategories. The intent of these studies was to determine the impact of such dense knowledge 
and high frequency of exposure on the gradedness of experts' subbasic level categories, and to investigate the degree to which CT and SF, in particular, influenced typicality ratings throughout the continuum of expertise. An overarching goal of the present research was to incorporate expertise effects into models of semantic memory that emphasize either the learning history of the individual (i.e., associationist models), or the internal attribute structure of the category (i.e., similarity-based comparison models). To this end, it is clear that both frequency of use (the hallmark of an associative architecture) and the degree to which an instance shares properties in common with a prototype (reflecting a content-addressable architecture; Hampton, 1997) exert joint influences on graded structure even when knowledge is very high. As previous research has indicated, judgments of typicality are informed by multiple sources of information (Barsalou, 1985; Hampton, 1998; Malt \& Smith, 1982). However, expertise may serve to tip the balance in favor of associationism. Among experts, the degree to which an exemplar is considered a good example appears to be primarily driven by the degree to which it is considered familiar. IF was correlated with SF, although IF did not contribute unique variance above and beyond the effects of SF to experts' typicality ratings. CT appears to have the most impact on typicality when categories are moderately heterogeneous and when domain-specific knowledge is average. CT influenced experts' typicality ratings of Australian exemplars in Study 1 and intermediate experts' ratings of subordinate level instances in Study 2, but appeared to become a less important determinant of typicality as knowledge increased.

The results from both Studies 1 and 2 indicate that in many respects, typicality gradients are similar for intermediate and advanced experts, and for subbasic categories corresponding to the taxonomic groupings of order and genus. Experts' heightened experience with a variety of domain exemplars, coupled with their knowledge of the degree to which features are shared across coordinate categories, leads them to compress judgments of typicality toward the "good example" end of the continuum. Although heightened salience of features related to species level differentiation promotes more efficient identification (Johnson \& Mervis, 1997; Murphy \& Lasseline, 1997; Tanaka \& Taylor, 1991), it does not appear to yield typicality gradients that mirror those at more inclusive hierarchical levels. Subbasic category members generally are considered by intermediate and advanced experts to be very good examples, with the exception of those that have seldom been encountered. As the specificity of category levels increases, so do the mean typicality ratings associated with category members. However, it is important to point out that this effect could likely obtain regardless of domain-specific knowledge levels. Unless one happens to catch novices on the cusp of learning about a new domain, one must generally recruit experts to study graded structure within narrow domains for which subcategory labels are not well known. It is likely that even when novices first learn to identify exemplars as members of categories such as wren and dachshund, judgments of typicality are biased toward the "good example" end of the continuum, simply because subordinate category structure yields few, if any, borderline category members.

\section{Familiarity as a Determinant of Typicality}

The present studies provide the first evidence that familiarity can be a principal determinant of typicality. When the categories for which typicality is rated are fairly specific, and when knowledge of those categories is relatively high, SF accounts for more variance in typicality than CT does. This study demonstrates an effect of SF on experts' typicality decisions, but the precise basis for this effect remains unclear. As stated earlier, the effect of SF on typicality ratings of Australian and American exemplars in Study 1 may have been an artifact of a contrast effect (recognizable exemplars were rated more typical than exemplars that could not be recognized). It also seems possible that expertise may jointly impact both subjective impressions of familiarity and similarity estimates, impacting determinations of typicality through the simultaneous yet independent influences of both factors.

Taken together with studies of young children's category inclusion and typicality decisions, these data suggest that familiarity exerts its greatest effects on typicality at the extremes of the knowledge continuum. Young children are abject novices on most domains because they have not yet encountered the breadth of category exemplars that adults have. Consequently, children tend to either exclude unfamiliar exemplars from their categories or to consider them to be relatively poor examples (e.g., Bauer, Dow, \& Hertsgaard, 1995; Bjorklund et al., 1983; White, 1982). Cultural familiarity also has been found to exert its greatest effect on category structure when knowledge of categories is relatively low. In a crosscultural comparison of Chinese and American children's conceptual structure, Lin et al. (1990) reported that associations between typicality and cultural familiarity were strongest for the youngest children studied. Gaps in the knowledge base may invariably lead to distortions in typicality decisions. When knowledge is very low, highly familiar instances may be indiscriminately considered typical, regardless of their relations to other exemplars included within the domain. Once individuals have had sufficient exposure to category members to enable them to abstract information concerning the degree to which features are shared, then CT may begin to exert a more pronounced effect on decisions of typicality.

Within experts' chosen domains, or domains that are highly salient within particular cultures, individuals are quite skilled at parsing categories into highly specific subcategories (e.g., Berlin, 1992; Boster, 1986; Malt, 1995). When domain-specific theoretical knowledge is extremely well developed, CT may be less relevant to decisions of typicality because of experts' heightened exposure to a broad variety of exemplars, coupled with 
their understanding of the degree to which features are shared by category members. Consequently, familiarity in the form of stored frequency information may be recruited as the basis for typicality. Research is necessary to determine whether this aspect of experts' conceptual structure has meaningful "cognitive consequences." For example, it is unclear whether speeded categorization decisions of experts would be predicted by SF, or whether experts' patterns of inductive inferences would be affected by the SF of the categories contained within premises. It also remains to be seen whether this pattern holds for both natural kind and artifact domains, or for categories at all levels of inclusiveness. It seems plausible that familiarity may play a role in determining experts' typicality judgments even for categories more inclusive than the basic level. For example, a zoologist who has spent his/ her career studying lemurs may consider lemurs to be extremely typical mammals, vertebrates, and animals, simply because of the salience they have gained through years of study.

\section{Interexpert Variations}

Different kinds of expertise may be associated with different kinds of interactions with object categories, and these interexpert variations may subsequently lead to variations in conceptual structure. The present studies included individuals whose domain of expertise was associated with the principal goal of field identification. Avid birders pride themselves on the diversity of specimens that can be successfully identified, and rarely do such experts constrain their interest to a single specific subcategory. In contrast, dog breeders tend to develop expertise on specific kinds of dogs, which culminates in different patterns of knowledge effects from those described for bird experts (Diamond \& Carey, 1986; Tanaka \& Taylor, 1991). Although experts' determinations of typicality have not yet been studied in domains such as these, it is possible that Barsalou's $(1985,1987)$ notion of ideals would inform graded structure within extremely specific (i.e., varietal, subsubordinate) categories. For example, ideals such as symmetry or fluidity of motion might inform decisions of typicality for expert breeders of dogs.

Within the same domain, different groups of experts may exhibit different goals and ideals as a function of their particular interests (Medin et al., 1997). Lynch et al. (2000) reported that tree experts' decisions of typicality were determined by ideals such as height and weediness, and that different groups of tree experts based their typicality decisions on different dimensions within the tree domain. Similar influences of ideals on goodness-ofexample ratings have been reported by Atran (1999) for Itzaj Maya folkbiology. Atran reports that "in each case for which we have Itzaj typicality ratings, the 'truest' (and often most taxonomically-typical taxa) are large, perceptually striking, culturally important, and ecologically prominent" (p. 177). When knowledge of domain exemplars is high, the psychological factors of goals, ideals, and SF play prominent roles in determining typicality. When knowledge is moderate, information available in the environment regarding the degree to which exemplars are similar to other exemplars appears to be most salient.

\section{Different Levels of Expertise}

Most investigations of the impact of expertise on human information processing have tended to contrast single groups of experts with single groups of novices (e.g., Boster \& Johnson, 1989; Chi, Glaser, \& Rees, 1982; Chi, Hutchinson, \& Robin, 1989) or to investigate differences in experts' performance across familiar and less familiar domains (e.g., Johnson \& Mervis, 1997; Tanaka \& Taylor, 1991). The present investigation included two groups of experts that differed in terms of their levels of familiarity with category members, despite the fact that each group averaged over 20 years experience in birding. Although our past research has indicated that individuals in these two knowledge groups exhibit significant differences in both quantitative and qualitative aspects of their classification strategies (Johnson \& Mervis, 1998), and in the levels of categorization that function as basic (Johnson \& Mervis, 1997), the present research suggests that individuals' decisions of typicality do not change markedly once intermediate levels of expertise have been attained. Both expert groups were influenced principally by SF when making typicality decisions, although intermediate experts were also influenced by CT when judging typicality in reference to specific genus level categories. It remains to be seen whether experts with different levels of experience are differentially affected by ideal dimensions within domains. Future work might be directed at determining whether ideal dimensions shift as a function of experience, perhaps from those based on relatively concrete features (e.g., color, movement) to dimensions that are more abstract (e.g., symmetry, ecology).

In conclusion, typicality decisions are affected by both environmental and psychological factors throughout the continuum of expertise, although the nature of the relations shifts as a function of both category level and level of knowledge. The relative homogeneity of subbasic level categories compresses decisions of typicality toward the "good example" end of the continuum, regardless of the extent to which perceptual learning has enhanced differentiability. A winter wren is a better example of wren than it is of passerine or bird, simply because of the degree to which members of subordinate categories share features. Nevertheless, experts tend to perceive category members even at relatively inclusive levels as better examples than nonexperts do. CT appears to impact typicality decisions most when knowledge levels are average, and is considerably less related to typicality once advanced levels of expertise have been attained. For experts in field identification, the best examples of categories tend to be those that are most familiar. Theoretical knowledge of concepts increases the diversity of factors that could potentially impact decisions of example goodness. Future research is needed to delineate which factors tend to be recruited by experts across a broad variety of artifact and natural kind domains. 


\section{REFERENCES}

Adams, A. K., \& Bullock, D. (1986). Apprenticeship in word use: Social convergence processes in learning categorically related nouns. In S. A. Kuczaj \& M. D. Barrett (Eds.), The development of word meaning: Progress in cognitive development research (pp.155-197). New York: Springer-Verlag.

AshCRAFT, M. H. (1978). Property norms for typical and atypical items from 17 categories: A description and discussion. Memory \& Cognition, 6, 227-232.

Atran, S. (1999). Itzaj Maya folkbiological taxonomy: Cognitive universals and cultural particulars. In D. Medin \& S. Atran (Eds.), Folkbiology (pp. 119-203). Cambridge, MA: MIT Press.

BARR, R. A., \& CAPLAN, L. J. (1987). Category representations and their implications for category structure. Memory \& Cognition, 15, 397-418.

BARSALOU, L. W. (1985). Ideals, central tendency, and frequency of instantiation as determinants of graded structure in categories. Journal of Experimental Psychology: Learning, Memory, \& Cognition, 11, 629-654.

BARSALOU, L. W. (1987). The instability of graded structure: Implications for the nature of concepts. In U. Neisser (Ed.), Concepts and conceptual development: Ecological and intellectual factors in categorization (pp. 101-140). New York: Cambridge University Press.

Bauer, P. J., Dow, G. A., \& Hertsgaard, L. A. (1995). Effects of prototypicality on categorization in 1- to 2-year-olds: Getting down to basic. Cognitive Development, 10, 43-68.

Berlin, B. (1992). Ethnobiological classification: Principles of categorization of plants and animals in traditional societies. Princeton, NJ: Princeton University Press.

Buorklund, D. F., Thompson, B. E., \& Ornstein, P. A. (1983). Developmental trends in children's typicality judgments. Behavior Research Methods \& Instrumentation, 15, 350-356.

Bовко, P. (1995). Correlation and regression. New York: McGraw-Hill.

Boster, J. S. (1986). Exchange of varieties and information between Aguaruna manioc cultivators. American Anthropologist, 88, 429-436.

Boster, J. S. (1988). Natural sources of internal category structure: Typicality, familiarity, and similarity of birds. Memory \& Cognition, 16, 258-270.

Boster, J. S., \& Johnson, J. C. (1989). Form or function: A comparison of expert and novice judgments of similarity among fish. American Anthropologist, 91, 866-889.

Brooks, L. R. (1987). Nonanalytic cognition. In U. Neisser (Ed.), Concepts and conceptual development: Ecological and intellectual factors in categorization (pp. 141-174). New York: Cambridge University Press.

ChI, M. T. H., Glaser, R., \& FARr, M. J. (EDS.) (1988). The nature of expertise. Hillsdale, $\mathrm{NJ}$ : Erlbaum.

Chi, M. T. H., Glaser, R., \& Rees, E. (1982). Expertise in problem solving. In R. Sternberg (Ed.), Advances in the psychology of human intelligence (Vol. 1, pp. 7-75). Hillsdale, NJ: Erlbaum.

Chi, M. T. H., Hutchinson, J. E., \& Robin, A. F. (1989). How inferences about novel domain-related concepts can be constrained by structured knowledge. Merrill-Palmer Quarterly, 35, 27-62.

Chumbley, J. I. (1986). The roles of typicality, instance dominance, and category dominance in verifying category membership. Journal of Experimental Psychology: Learning, Memory, \& Cognition, 12, 257-267.

Diamond, R, \& Carey, S. (1986). Why faces are and are not special: An effect of expertise. Journal of Experimental Psychology: General, 115, 107-117.

FISHER, J. (1959). The twisted pear and the prediction of behavior. Journal of Consulting Psychology, 23, 400-405.

Goвво, C., \& Chi, M. (1986). How knowledge is structured and used by expert and novice children. Cognitive Development, 1, 221-237.

HAMPton, J. A. (1997). Associative and similarity-based processes in categorization decisions. Memory \& Cognition, 25, 625-640.

HAMPTON, J. A. (1998). Similarity-based categorization and fuzziness of natural categories. In S. A. Sloman \& L. J. Rips (Eds.), Similarity and symbols in human thinking (pp. 51-79). Cambridge, MA: MIT Press.

Johnson, K. E. \& Mervis, C. B. (1997). Effects of varying levels of expertise on the basic level of categorization. Journal of Experimental Psychology: General, 126, 248-277.

Johnson, K. E., \& Mervis, C. B. (1998). Impact of intuitive theories on feature recruitment throughout the continuum of expertise. Memory \& Cognition, 26, 382-401.

KALISH, C. W. (1995). Essentialism and graded membership in animal and artifact categories. Memory \& Cognition, 23, 335-353.

KeIL, F. C. (1994). Explanation, association, and the acquisition of word meaning. In L. Gleitman \& B. Landau (Eds.), The acquisition of the lexicon (pp. 169-196). Cambridge, MA: MIT Press.

Keller, C. E., \& Keller, T. C. (1993). Birds of Indianapolis: A guide to the region. Bloomington: Indiana University Press.

Kučera, H., \& Francis, W. N. (1967). Computational analysis of present-day American English. Providence, RI: Brown University Press.

Kurbat, M. A., \& Smith, E. E. (1994). Categorization, typicality, and shape similarity. In A. Ram \& K. Eiselt (Eds.), Proceedings of the Sixteenth Annual Conference of the Cognitive Science Society Meetings. Hillsdale, $\mathrm{NJ}$ : Erlbaum.

Lin, P., Schwanenflugel, P. J., \& Wisenbaker, J. M. (1990). Category typicality, cultural familiarity, and the development of category knowledge. Developmental Psychology, 26, 805-813.

López, A. Atran, S., Coley, J. D., Medin, D. L., \& Smith, E. E. (1997). The tree of life: Universal and cultural features of folkbiological taxonomies and inductions. Cognitive Psychology, 32, 251-295.

Lynch, E. B., Coley, J. D., \& Medin, D. L. (2000). Tall is typical: Central tendency, ideal dimensions, and graded structure among tree experts and novices. Memory \& Cognition, 28, 41-50.

MALt, B. C. (1995). Category coherence in cross-cultural perspective. Cognitive Psychology, 29, 85-148.

Malt, B. C., \& Smith, E. E. (1982). The role of familiarity in determining typicality. Memory \& Cognition, 10, 69-75.

Malt, B. C., \& Smith, E. E. (1984). Correlated properties in natural categories. Journal of Verbal Learning \& Verbal Behavior, 23, 250269.

McCloskey, M. E., \& GlucksBerg, S. (1978). Natural categories: Well defined or fuzzy sets? Memory \& Cognition, 6, 462-472.

Medin, D. L. (1989). Concepts and conceptual structure. American Psychologist, 44, 1469-1481.

Medin, D. L., Lynch, E. B., \& Coley, J. D. (1997). Categorization and reasoning among tree experts: Do all roads lead to Rome? Cognitive Psychology, 32, 49-96.

Mervis, C. B., Catlin, J., \& Rosch, E. (1976). Relationships among goodness-of-example, category norms, and word frequency. Bulletin of the Psychonomic Society, 7, 283-284.

Mervis, C. B., \& PANI, J. R. (1980). Acquisition of basic object categories. Cognitive Psychology, 12, 496-522.

Murphy, G. L. (1993). Theories and concept formation. In I. Van Mechelen, J. Hampton, R. Michalski, \& P. Theuns (Eds.), Categories and concepts: Theoretical views and inductive data analysis (pp. 173200). New York: Academic Press.

MurPhy, G. L., \& Brownell, H. H. (1985). Category differentiation in object recognition: Typicality constraints on the basic category advantage. Journal of Experimental Psychology: Learning, Memory, \& Cognition, 11, 70-84.

MurPhy, G. L., \& Lasseline, M. E. (1997). Hierarchical structure in concepts and the basic level of categorization. In K. Lamberts \& D. Shanks (Eds.), Knowledge, concepts, and categories (pp. 93-131). Cambridge, MA: MIT Press.

Murphy, G. L., \& Medin, D. L. (1985). The role of theories in conceptual coherence. Psychological Review, 92, 289-316.

MurPhy, G. L., \& Wright, J. C. (1984). Changes in conceptual structure with expertise: Differences between real-world experts and novices. Journal of Experimental Psychology: Learning, Memory, \& Cognition, 10, 144-155.

Palmer, C. F., Jones, R. K., Hennesy, B. L., Unze, M. G., \& Pick, A. D. (1989). How is a trumpet known? The "basic object level" concept and the perception of musical instruments. American Journal of Psychology, 102, 17-37.

Proctor, R. W., \& DutTA, A. (1995). Skill acquisition and human performance. Thousand Oaks, CA: Sage.

RIPS, L. J. (1975). Inductive judgments about natural categories. Journal of Verbal Learning \& Verbal Behavior, 14, 665-681.

Rips, L. J., Shoben, E. J., \& Sмiтh, E. E. (1973). Semantic distance and 
the verification of semantic relations. Journal of Verbal Learning \& Verbal Behavior, 12, 1-20.

Rosch, E. (1975). Cognitive representations of semantic categories. Journal of Experimental Psychology: General, 104, 192-233.

Rosch, E. (1978). Principles of categorization. In E. Rosch \& B. B. Lloyd (Eds.), Cognition and categorization (pp. 27-48). Hillsdale, NJ: Erlbaum.

Rosch, E. \& Mervis, C. B. (1975). Family resemblances: Studies in the internal structure of categories. Cognitive Psychology, 7, 573-605.

Rosch, E., Mervis, C. B., Gray, W. D. Johnson, D. M., \& BoyesBraem, P. (1976). Basic objects in natural categories. Cognitive Psychology, 8, 382-439.

Rosch, E., Simpson, C., \& Miller, R. S. (1976). Structural bases for typicality effects. Journal of Experimental Psychology: Human Perception \& Performance, 2, 491-502.

Schyns, P. G., Goldstone, R. L., \& Thibaut, J. (1998). The development of features in object concepts. Behavioral \& Brain Sciences, 21, $1-54$.

Smith, E. E., \& Medin, D. L. (1981). Categories and concepts. Cambridge, MA: Harvard University Press.

Smith, E. E., Shoben, E. J., \& Rips, L. J. (1974). Structure and process in semantic memory: A feature model for semantic decisions. Psychological Review, 81, 214-241.

StORMS, G., \& DE BoECK, P. (1997). Formal models for intra-categorical structure that can be used for data analysis. In K. Lamberts \& D. Shanks (Eds.), Knowledge, concepts, and categories (pp. 439 459). Cambridge, MA: MIT Press.

TANAKA, J. W., \& TAYLOR, M. (1991). Object categories and expertise: Is the basic level in the eye of the beholder? Cognitive Psychology, 23, 457-482.

Tversky, B., \& Hemenway, K. (1984). Objects, parts, and categories. Journal of Experimental Psychology: General, 113, 169-193.

White, T. G. (1982). Naming practices, typicality, and underextension in child language. Journal of Experimental Child Psychology, 33, 324-346.

WisniewsKi, E. J., \& Medin, D. L. (1994). On the interaction of theory and data in concept learning. Cognitive Science, 18, 221-281.

\section{NOTES}

1. In evaluating differences between groups of individuals with varying levels of knowledge, it is important to consider how attenuation of range for any of the variables considered may impact the pattern of results. Indirect range restriction is almost certainly going to occur whenever experts (who possess highly specialized knowledge that most individuals lack) make decisions about domain-specific information. Significant correlations that obtain within knowledge groups are almost certainly quite robust, since range restriction typically reduces the likelihood of detecting such relations, particularly given the small sample sizes that characterize research on expertise (Bobko, 1995; Fisher, 1959). The possibility that attenuation of range impaired our ability to detect certain relations in the present studies cannot be definitively ruled out. However, we consider it unlikely that range restriction hindered our ability to detect a relation between novices' ratings of familiarity and typicality in the present study. We deliberately included several local passerines that are typical "backyard birds" (e.g., robin, jay, cardinal) in order to ensure that all participants would rate some species as moderately familiar. Novices tended to rate cardinal as highly familiar, but not very typical, presumably because of its brilliant red plumage. Its color enables it to be noticed frequently (hence increasing familiarity), while at the same time increasing its distinctiveness. Second, the standard deviations associated with novices' familiarity ratings were comparable to those of intermediate experts for both North American $\left(S D_{\text {int }}\right.$ $\left.=1.92, S D_{\text {nov }}=1.31\right)$ and Australian $\left(S D_{\text {int }}=.78, S D_{\text {nov }}=.87\right)$ exemplars.

2. For the Australian passerines, HCT and LCT exemplars were identical for both expert and novice CT indices. For the American passerines, two exemplars appeared in different $\mathrm{CT}$ groups depending on which type of CT index was used (American goldfinch was LCT based on a median split of the novice-CT index but HCT based on a median split of the expert-CT index, and common grackle was HCT based on a median split of the novice-CT index, but LCT based on a median split of the expert-CT index). Identical patterns of results obtained for both CT indices, so only data based on a median split of the novice-CT index are presented here.

3. Natural logarithms, rather than raw scores, were summed in order to avoid distorting the indices of CT. Since it is not necessarily reasonable to assume that the difference between features with raw scores of 1 and 2 is equivalent to the difference between features with raw scores of 4 and 5, features were weighted with the natural logarithm of the score representing the extent to which it was distributed across members of the subordinate category. Rosch and Mervis (1975) found significant correlations between typicality ratings and both logarithmic and nonlogarithmic measures of family resemblance.

APPENDIX A

North American and Australian Passerine Species Included in Study 1

\begin{tabular}{|c|c|c|c|}
\hline \multicolumn{2}{|c|}{ North American } & \multicolumn{2}{|c|}{ Australian } \\
\hline Common Name & Scientific Name & Common Name & Scientific Name \\
\hline American goldfinch* & Carduelis tristis & Black grasswren & Amytornis housei \\
\hline American robin* & Turdus migratorius & Cinnamon quail-thrush & Cinclosoma cinnamomeum \\
\hline Blue jay* & Cyanocitta cristata & Crested shrike-tit* & Falcunculus frontatus \\
\hline Brown thrasher & Toxostoma rufum & Crimson finch* & Neochmia phaeton \\
\hline Cedar waxwing & Bombycilla cedrorum & Golden bowerbird* & Prionoduranewtoniana \\
\hline Cerulean warbler & Dendroica cerulea & Jacky winter* & Microecafascinans \\
\hline Common grackle* & Quiscalus quiscula & Magnificent riflebird* & Ptiloris magnificus \\
\hline Common raven $*$ & Corvus corax & Magpie-lark & Grallina cyanoleuca \\
\hline Eastern bluebird* & Sialia sialis & Noisy pitta* & Pitta versicolor \\
\hline Golden-crowned kinglet & Regulus satrapa & Painted honeyeater & Grantiella picta \\
\hline Hermit thrush* & Catharus guttatus & Red-browed treecreeper & Climacteris erythrops \\
\hline Northern cardinal* & Cardinalis cardinalis & Restless flycatcher & Myiagra inquieta \\
\hline Northern oriole & Icterus galbula & Rufous shrike-thrush* & Colluricincla megarhyncha \\
\hline Purple finch & Carpodacus purpureus & Speckled warbler* & Chthonicola sagittata \\
\hline Rose-breasted grosbeak & Pheucticus ludovicianus & Splendid wren* & Malurus splendens \\
\hline Snow bunting* & Plectrophenaxnivalis & Striated pardalote & Pardalotus striatus \\
\hline Song sparrow* & Melospiza melodia & Yellow chat & Epthianuracrocea \\
\hline Summer tanager & Piranga olivacea & Yellow white-eye* & Zosterops lutea \\
\hline
\end{tabular}

*Included in the typicality and familiarity rating phase of Study 1. 
APPENDIX B

Mean Scores Generated for American and Australian Exemplars Across Groups of Participants*

\begin{tabular}{llcccccccc}
\hline Residence & Exemplar & Exp CT & Nov CT & AE Typ & IE Typ & Nov Typ & AE Fam & IE Fam & Nov Fam \\
\hline American & Bluebird & 4.89 & 2.13 & 1.25 & 1.50 & 2.95 & 1.25 & 1.50 & 4.60 \\
& Bunting & 5.30 & 4.35 & 2.17 & 3.65 & 4.40 & 2.17 & 3.65 & 6.05 \\
& Cardinal & 5.19 & 5.08 & 1.33 & 1.30 & 4.50 & 1.33 & 1.30 & 1.55 \\
& Goldfinch & 5.03 & 4.29 & 1.33 & 1.60 & 3.75 & 1.33 & 1.60 & 5.65 \\
& Grackle & 5.22 & 1.48 & 3.58 & 4.90 & 4.50 & 3.58 & 4.90 & 5.15 \\
& Jay & 5.17 & 3.12 & 2.58 & 2.60 & 3.75 & 2.58 & 2.60 & 2.65 \\
& Raven & 5.86 & 5.14 & 4.83 & 6.20 & 4.50 & 4.83 & 6.20 & 2.90 \\
& Robin & 4.99 & 2.24 & 1.41 & 1.40 & 3.30 & 1.41 & 1.40 & 2.85 \\
& Sparrow & 5.22 & 1.07 & 1.83 & 1.50 & 6.20 & 1.83 & 1.50 & 4.80 \\
& Thrush & 5.69 & 4.73 & 2.17 & 1.90 & 4.00 & 2.17 & 1.90 & 4.75 \\
Australian & Bowerbird & 5.33 & 4.21 & 3.33 & 4.45 & 3.50 & 6.17 & 6.80 & 6.35 \\
& Finch & 5.13 & 2.08 & 3.33 & 3.90 & 3.55 & 5.67 & 6.30 & 6.35 \\
& Jacky winter & 5.00 & 1.27 & 2.42 & 2.95 & 3.75 & 6.33 & 6.00 & 5.75 \\
& Pitta & 5.00 & 4.62 & 5.00 & 5.45 & 3.35 & 5.83 & 6.65 & 6.60 \\
& Riflebird & 6.17 & 5.19 & 5.25 & 5.75 & 3.30 & 5.83 & 6.60 & 6.50 \\
& Shrike-thrush & 4.58 & 2.42 & 3.33 & 4.10 & 3.60 & 6.25 & 6.45 & 6.10 \\
& Shrike-tit & 5.50 & 4.02 & 4.08 & 4.75 & 3.80 & 6.25 & 6.60 & 6.45 \\
& Warbler & 4.96 & 1.30 & 3.42 & 3.10 & 3.10 & 6.58 & 6.70 & 4.85 \\
& White-eye & 4.74 & 2.21 & 2.33 & 2.70 & 2.80 & 5.08 & 5.10 & 5.90 \\
& Wren & 5.18 & 5.06 & 2.83 & 3.60 & 3.40 & 4.83 & 6.35 & 6.05 \\
\hline
\end{tabular}

Note-AE, advanced experts; IE, intermediate experts; Nov, novices; CT, central tendency; Typ, typicality; Fam, familiarity.

*To facilitate interpretation, raw means (rather than means based on standardized reversed scores) are presented.

APPENDIX C

Mean Scores for Subordinate Category Exemplars in Study 2*

\begin{tabular}{|c|c|c|c|c|c|c|}
\hline \multirow[b]{2}{*}{ Species } & \multirow[b]{2}{*}{$\mathrm{CT}$} & \multicolumn{2}{|c|}{$\mathrm{IE}$} & \multicolumn{2}{|c|}{$\mathrm{AE}$} & \multirow[b]{2}{*}{$\mathrm{IF}^{* *}$} \\
\hline & & AE Typ & Typ & Fam & IE Fam & \\
\hline \multicolumn{7}{|l|}{ Stimulus Set 1} \\
\hline Field sparrow & 29.25 & 1.40 & 2.09 & 1.20 & 1.54 & 6 \\
\hline Henslow's sparrow & 28.44 & 3.00 & 3.54 & 2.00 & 4.36 & 4 \\
\hline Lark sparrow & 27.92 & 2.60 & 3.00 & 2.80 & 4.54 & 3 \\
\hline Song sparrow & 31.91 & 1.00 & 1.18 & 1.00 & 1.09 & 7 \\
\hline White-throated sparrow & 26.77 & 1.40 & 1.64 & 1.40 & 1.27 & 6 \\
\hline Red-eyed vireo & 31.26 & 1.60 & 1.27 & 1.00 & 1.54 & 6 \\
\hline Solitary vireo & 26.12 & 1.80 & 2.00 & 2.20 & 2.63 & 5 \\
\hline Warbling vireo & 27.11 & 2.60 & 2.36 & 1.60 & 2.00 & 6 \\
\hline White-eyed vireo & 28.20 & 1.20 & 1.55 & 1.40 & 1.27 & 6 \\
\hline Yellow-throated vireo & 32.08 & 1.20 & 2.09 & 1.40 & 2.55 & 5 \\
\hline \multicolumn{7}{|l|}{ Stimulus Set 2} \\
\hline Black-and-white warbler & 29.22 & 1.57 & 1.56 & 1.28 & 1.44 & 6 \\
\hline Hooded warbler & 35.93 & 1.14 & 1.11 & 1.43 & 2.44 & 4 \\
\hline Kentucky warbler & 38.01 & 1.29 & 1.44 & 1.86 & 3.55 & 5 \\
\hline Pine warbler & 35.69 & 1.57 & 1.67 & 1.43 & 3.33 & 4 \\
\hline Worm-eating warbler & 32.63 & 2.28 & 2.33 & 2.00 & 3.33 & 4 \\
\hline Bewick's wren & 25.43 & 1.71 & 2.11 & 2.14 & 4.67 & 2 \\
\hline Carolina wren & 29.13 & 1.28 & 1.33 & 1.00 & 1.11 & 7 \\
\hline House wren & 35.09 & 1.29 & 1.00 & 1.00 & 1.22 & 6 \\
\hline Marsh wren & 24.97 & 1.86 & 1.78 & 1.57 & 3.67 & 4 \\
\hline Winter wren & 27.46 & 1.57 & 1.56 & 1.43 & 2.67 & 5 \\
\hline
\end{tabular}

Note-CT, central tendency; AE, advanced experts; Typ, typicality; Fam, familiarity; IF, instantiation frequency. *To facilitate interpretation, raw means (rather than means based on standardized ratings) are presented. **IF scores assigned to residency codes (from Keller \& Keller, 1993): 7 = permanent resident; $6=$ common migrant/visitor; $5=$ uncommon migrant/visitor; $4=$ rare migrant/visitor; $3=$ very rare migrant/visitor; $2=$ accidental $1=$ exotic/extirpated. 